\title{
ROLE OF HERBS IN TUBERCULOSIS: A COMPILATION
}

\section{Dr. J Mohanasundaram, Dean \& Professor of Pharmacology}

Shri Sathya Sai Medical College and Research Institute, Sri Balaii Vidyapeeth, Nellikuppam, Kancheepuram Dist., Tamil Nadu - 603 108, India.

:

Abstract
commonty used household remedies such as spices, condiments, fruits, vegetables, flowers
etc and other herbs based on their effectiveness in inhibiting Mycobacterium. tuberculosis both
normal or multidrug resistant strains or their ability to prevent anti tuberculous drug induced
adverse effects such as hepatotoxicity. The herbs or formulations which have relevance to
tuberculosis andscientifically evaluated invitro or invivo in animal models or in clinical studies
and found to have positive effects have been included in this compilation.
Key Words: Anti-tuberculous herbs,Multi drug resistant Tuberculosis, Anti tuberculous drug
induced Toxicity

\section{Introduction}

The disease Tuberculosis is in existence since time immemorial ${ }^{(1)}$. The specific Chemotherapy with effective agents were available only from mid-20th century. Complementary and alternative medicine including herbs $\&$ nutritional agents are in use with adjunct role ${ }^{(2)}$. After the introduction of Specific Chemotherapeutic agents the role of herbs have turned in to different dimensions such as:

a. Amelioration of toxicity induced by anti tubercular drugs like Rifampicin, INH, Ethambutol etc.

b. Adjuvant role in overcoming Multi Drug Resistance.

\section{Discussion}

In this article the herbs which have some scientific evidence on their effect in vitro or invivo or in clinical studies with reference to Tuberculosis have been enumerated. Agents that are being used as general health restorers and immune boosters including Common house hold remedies like vegetables, fruits, spices, condiments are enlisted below with their role against Tuberculosis are:

Green Tea - (Theasinensis)is rich in ant-oxidants and a general immune-booster which will help in fighting tuberculosis. green tea extract administration for one weekreverted back the oxidative stress parameters induced by MT infection in miceto near normal levels as evidenced by a fall in catalase, glutathione peroxidase, total thiol and extent of lipid peroxidation with concomitant increase in the levels of SOD and reduced glutathione in infected animals ${ }^{(3)}$

Garlic - (Allium sativum) hasanti bacterial property against Tubercle bacilli as it contains sulphur. Garlic also contains allicin and ajoene which helps to inhibit the bacterial growth.Rao and coworkers demonstrated, as early as in 1946 , the in vitro inhibitory effect of allicin on the growth of M.tuberculosis ${ }^{(4)}$.Liu et al has shown that garlicin can inhibit MTB protein synthesis and also inhibit bacterial rotamase, thus preventing DNA replication and degradation resulting in MTB death. ${ }^{(5)}$ 
Onion - (Allium cepa) is reported for the first time to possess inhibitory activity against isolates of MT by Gupta et $\mathrm{al}^{(13)}$

Black pepper (Piper nigrum) - Pepper has anti inflammatory properties which will help to reduce the inflammation. An active principle of pepper Piperineby reducing the required dose of expensive toxic Rifampicin by 60 percent,there by reducing the cost and side effects of Rifampicin and also effective against Tuberculosis. ${ }^{(6)}$

Cinnamomum - A study conducted in India showed that extracts of Cinnamomumzeylanicum (CZ) had activity against M. tuberculosiswith an MIC of $100 \mu \mathrm{g} / \mathrm{ml}$ for water extract and MIC-200 $\mu \mathrm{g} / \mathrm{ml}$ for ethanolic extract ${ }^{(7)}$ and a study conducted inTurkey showed that $\mathrm{M}$. tuberculosisstrains $\mathrm{H} 37 \mathrm{Rv}$ and $\mathrm{H} 37 \mathrm{Ra}$ had MIC of $1024 \mu \mathrm{g} / \mathrm{ml}$ and $512 \mu \mathrm{g} / \mathrm{ml}$ respectively and MBC was $>2048 \mu \mathrm{g} / \mathrm{ml}$ of CZ for both strains. ${ }^{(8)}$

Mint (Menthapiperita) - has anti bacterial property and helps in the healing of the tissues affected by tuberculosis. The in vitro antibacterial activities of ethanolic extracts showed $0.39 \mathrm{mg} / \mathrm{ml}$ consistency of M. spicata and $100 \mathrm{mg} /$ $\mathrm{ml}$ consistency of $\mathrm{M}$. piperita as the least concentrations which inhibit growth of Mycobacterium. bovis in comparison with isoniazid. ${ }^{(9)}$

Annonasquamosa - Administration of methanolic extracts of Annonasquamosa prevented isoniazid-rifampicin-induced elevation in the levels of serum diagnostic liver marker enzymes in experimental groups of rats.Flavanoids were thought to be the main bioconstituent responsible for the hepatoprotective activity against anti tubercular drug induced toxicity ${ }^{(10)}$

Drumstick leaves (Moringaoleifera) - have antibacterial and anti- inflammatory properties which will help to eliminate the bacteria from the lungs. The leaf ethyl acetate extract of M. oleifera showed the highest activity against Mycobacterium madagascariense with minimum inhibition concentration (MIC) value of $0.37381 \mathrm{mg} / \mathrm{ml}$ while the seeds ethyl acetate extracts had MIC value of $0.37381 \mathrm{mg} /$ $\mathrm{ml}$ against both $\mathrm{M}$. madagascariense and M.indicuspranii. ${ }^{(11)}$

Zingiberofficinalis - [10]-gingerol isolated from ginger rhizome, has been reported as active inhibitor of $\mathrm{M}$. avium and $\mathrm{M}$. tuberculosis in vitro ${ }^{(12)}$

Apart from the above common ingredients other agents like Banana, Custard apple, gooseberry, orange, pineapple, walnut are also supposed to have beneficial effects in Tuberculosis by virtue of theirnutitional value vitamin contents and general immune boosting effects.

\section{Herbs effective against (drug sensitive and Multidrug resistant) Tuberculosis:}

Acalyphaindica, Adhatodavasica, Allium cepa, Allium sativum and Aloe vera (Aqueous extracts of leaves of) exhibited inhibitory activity of 95, 32, 37, 72, 32 per cent, respectively against MDR isolate DKU-156 and 68, 86, 79, 72, 85 per cent, respectively for another MDR isolate JAL-1236,, of M. tuberculosis. in L-J medium. ${ }^{(13)}$

Andrographispaniculata - Themethanolic extract of A. paniculata showed maximum antimycobacterial activity at $250 \mu \mathrm{g} / \mathrm{ml}$ against all the tested strains of $\mathrm{M}$. tuberculosis (H37Rv, MDR, and drug sensitive). Based on bioassay guided fractionation, andrographolide was identified as the potent molecule. ${ }^{(14)}$

Artemisia afra - Tuber. A study showed that A. afra has in vitro anti-mycobacterial activity, modulates pulmonary inflammation in early mycobacterial infection, and suggest that the mouse experimental tuberculosis model may serve as a useful assay for evaluating the utility of phytotherapy. ${ }^{(15)}$

Azadirachtaindica - The neem extract suppressed MTBinfected monocytes in a dose-dependent manner $(\mathrm{P}<0.001)$ in the expressions of secreted TNF- $\alpha$, iNOS and MTB Ag85 respectively in $24 \mathrm{hr}$ culture supernatants of MTB-infected monocytes. ${ }^{(16)}$

Berberis vulgaris - Barberry or is highly effective in relieving TB symptoms and is used to complement conventional treatment. The active ingredient in barberry is berberine which has bacterial properties and aids in killing the tuberculosis. Berberine can inhibit MTB in vitro, and the activities are concentration dependent. ${ }^{(17,18)}$

Calendula officinalis - In a study the Minimum Inhibitory Concentration of aquous (aq) and ethanolic(E) extracts of C.officinalisagainst M. tuberculosisstrains C: ATCC 35808 and H37RV ATCC 25618 and clinical isolates of M. tuberculosis were $125 \mu \mathrm{g} / \mathrm{ml}(\mathrm{Aq}), 3.9 \mu \mathrm{g} / \mathrm{ml}$ (E) respectively and the Minimum Bactericidal Concentration were $250 \mu \mathrm{g} / \mathrm{ml}$ (Aq) , $7.8 \mu \mathrm{g} / \mathrm{ml}$ (E).The ethanolic extract can be tried as antibacterial agents against MDR-TB. ${ }^{(19)}$

Carica papaya - Theethanolic extract of leaves and seeds of Carica papayashowed anti-tb activity against clinical strains of sensitive and drug resistant M. tuberculosis (pyrazinamide, streptomycin, ciprofloxacin) in an in-vitro bioassay. ${ }^{(20)}$

Catharanthusroseus - C.roseus and Piperine were evaluated against Ofloxacin resistant $\mathrm{M}$. tuberculosis which showed 
that both act as efflux pump inhibitor and synergistically more active and the percentage of relative inhibitiory zone of C.roseus was $133 \%$ and piperine was $111 \%{ }^{(21)}$

Chenopodiumambrosioides $-\mathrm{n}$ acetone extract of $\mathrm{C}$. ambrosioides was effective against a resistant $\mathrm{H} 37 \mathrm{Rv}$ strain of M. tuberculosis at $0,1 \mathrm{~g} / \mathrm{mL}^{(22)}$

Cola nitida and C. milleni - Methanol extract of root bark of both C. nitida and milleniwere found to be potent against both $\mathrm{M}$. bovis and strains of $\mathrm{M}$. vaccae. ${ }^{(23)}$

Croton pseudopulchellus, Ekebergiacapensis, Eucleanatalensis, Nidorellaanomala and Polygala myrtifolia - A study on the South African medicinal plants used to treat pulmonary diseases for activity against drug-resistant and drug-sensitive strains of $\mathrm{M}$. tuberculosisrevealed that the minimal inhibitory concentration of Croton pseudopulchellus, Ekebergiacapensis, Eucleanatalensis, Nidorellaanomala and Polygala myrtifolia was $0.1 \mathrm{mg} / \mathrm{ml}$ against the H37Rv strain and the. Extracts of Chenopodiumambrosioides, Ekebergiacapensis, Eucleanatalensis, Helichrysummelanacme, Nidorellaanomala and Polygala myrtifolia were active against the resistant strain at $0.1 \mathrm{mg} / \mathrm{ml} .^{(24)}$

Curcuma pseudomonata (Hill Turmeric) - Hexane, chloroform, ethyl acetate and methanol extracts of rhizome of Curcuma pseudomontana showed activity against M.tuberculosisstrain $\mathrm{H} 37 \mathrm{RV}$ at 100 and $50 \mathrm{mg} / \mathrm{ml}^{.}{ }^{(25)}$

Eucleanatalensis - A binaphthoquinoid, diospyrin, was isolated from Eucleanatalensis showed activity against drugsensitive and drug-resistant strains of $\mathrm{M}$. tuberculosiswith an MIC of $100 \mathrm{microg} / \mathrm{ml}$ for all. ${ }^{(26)}$

Morindacitrifolia - A crude ethanol extract and hexane fraction from Morindacitrifolia Linn. (Rubiaceae) show antitubercular activity. E-Phytol, a mixture of the two ketosteroids, and the epidioxysterol derived from campesta5,7,22-trien-3beta-ol all show pronounced antitubercular activity. ${ }^{(27)}$

Peristrophebicalyculata - A yellow-brown essential oil can be extracted by distillation, shows in vitro activity against the growth of various strains of MT. ${ }^{(28)}$

Salvia hypargeia - A new abietanediterpenoidHypargenin $\mathrm{F}$ isolated from the root extracts of Salvia hypargeia was active against $\mathrm{MT} .{ }^{(29)}$

Solanumtorvum - Methyl caffeate isolated from Solanumtorvum showed moderate antimicrobial and prominent antimycobacterial activities with minimum inhibitory con- centration (MIC) of $8 \mu \mathrm{g} / \mathrm{ml}$ against $\mathrm{M}$. tuberculosis $\mathrm{H}^{(37)}$ $\mathrm{Rv}$ and $\mathrm{Rif}(\mathrm{R})$ strains. ${ }^{(30)}$

Withaniasomnifera - a herb known as Aswagandha and used in Ayurvedic medicine which contains many useful medicinal chemicals, including withanolides (steroidal lactones), alkaloids, which was shown to enhance absorption of Antituberculous drugs isoniazid and pyrazinamide and hastened the AFB sputum conversion in to negativity and reduction in ESR hence useful as an Adjunct therapy with Anti tubercular drugs. ${ }^{(31)}$

Zizyphusmauritiana Mauritine M \& nummularines $\mathrm{H}$ - isolated from $\mathrm{MeOH}$ extract obtained from the root of the Ziziphusmauritiana demonstrated antimycobacterial activity against M.tuberculosiswith the MIC of 72.8 and $4.5 \mu \mathrm{M}$, respectively. ${ }^{(32)}$

\section{Herbs which alleviate Anti Tuberculous Therapy inducedhepato toxicity:}

Boerhaaviadiffusa - A study showed that flavanoids and tannins also B-sitsterol have both antioxidant and antihypercholesterol properties and may be responsible for the protective activity of Boerhaaviadiffusa against antitubercular drugs. ${ }^{(33)}$

Bombaxcieba - Flavanoids and sequiterpenoids which scavenge free radicals were thought to be reason for effectiveness of $\mathrm{B}$. cieba plant against anti-tubercular drug toxicity. ${ }^{(34)}$

Cassia fistula - Anti-tubercular protective action of C. fistula is due to presence of flavanoids present in it.. ${ }^{(35)}$

Cnidoscoluschayamansa - C. chayamansa significantly prevented Rifampicin-Isoniazid-induced elevation in the levels of serum diagnostic liver marker enzymes aspartate amino transferase, alanine amino transferase and alkaline phosphatase level in experimental groups of rats. ${ }^{(36)}$

Curcuma longa and Tinosporacordifolia - combination prevented anti-tuberculosis treatment (ATT) induced hepatotoxicity and the incidence and severity of hepatotoxicity was significantly lower in trial group. ${ }^{(37)}$

Cuscutareflexa - A study of methanol extract of aerial parts of Cuscutareflexa revealed protective effect on hepatotoxicity induced by antitubercular drugs in rats. ${ }^{(38)}$

Garciniaindica - Aq. Extract of Garciniaindicaattenuated the antitubercular drug (ATD)-induced elevated levels of aspartate aminotransferase, alanine transaminase, alkaline phosphatase, bilirubin, and malondialdehyde and restored 
the ATD-depleted levels of glutathione (GSH), superoxide dismutase, catalase, GSH peroxidase, and GSH reductase. ${ }^{(39)}$

Ginkobiloba - Two major mechanisms that may be responsible for hepatoprotective activity of G.biloba are flavanoids which may be responsible for scavenging activity of reactive oxygen species that were produced due to toxicity caused by anti TB drugs. ${ }^{(40)}$

Jasminumgrandiflorum - JG leaves extract treatment in rats revealed hepatoprotective activity in isoniazid induced liver damage. ${ }^{(41)}$

Ocimumsanctum - Co-administration of OS leaf extract along with the anti - tubercular drugs significantly prevented all the biochemical and histological alterations caused by the antitubercular drugs and significantly reversed all the histopathological scores. ${ }^{(42)}$

Picorhizakurroa - By its counter acting effects of free radicals by the presence of electrophillic constituent, picroside II and kurkoside or to an activated conjugation of anti TB drugs with GSH in liver P. kurroa ameliorated hepatotoxic effect induced by Rifampicin in rats. ${ }^{(43)}$

Phyllanthusfraternus - (Bhumyamalaki) showedhepatoprotective effect in a 12 weeks clinical study on patients receiving Anti tuberculartreatment. ${ }^{(44)}$

Pulsatillachinensis - has been shown to inhibit MTB in vitro. It can also reduce the hepatotoxicity jnduced by rifampicin and isoniazid hence has a protective action against liver damage and combining this in antitubercular therapy can reduce the side effects. ${ }^{(45)}$

Rhodomyrtustomentosa - It was found thatphenolic compounds were responsible for the protective activity of this plant against antitubercular drugs induced hepatic damage. ${ }^{(46)}$

Sophoraflavescens - has a monomeric alkaloid matrine, which can improve the body's immune system, resist inflammation, inhibits bacteria, and protects the liver hence useful in Tuberculosis. ${ }^{(47)}$

Spirulina maxima - protects liver from Isoniazid and Rifampicin drug induced toxicity. ${ }^{(48)}$

\section{Herbal Formulations:}

Liv-600- Herbal formulation - Liv-600 an Ayurvedic formulation containing hydroalcoholic extract of Daruharidra (Berberisaristata) roots, Kakmachi (Solanumnigrum) whole plant, Ghritakumari (Aloe vera) ariel parts was administered to 10 patients with Tuberculosis in a Clinical study for 12 weeks from initiation of Anti Tubercular Treatment. Liver functions were periodically monitored which revealed the hepatoprotective efficiency of this formulation over the placebo at the end of the study. ${ }^{(44)}$

A Chinese medicinal formulation for treating tuberculosis of intestine CN 102847027 A - A patent related to the invention of a Chinese medicinal formulation for treating tuberculosis of intestine, comprising Poriacocos, Poria, Semen ArmeniacaeAmarum, Coixlacryma-jobi seed, Dioscoreaopposita, Radix Adenophorae and/or Radix Glehniae, stir-baked Radix Stemonae, CrinisCarbonisatus, Limonitum, RhizomaCynanchiStauntonii, Atractylodesmacrocephala, Terminaliachebula, HerbaPlantaginis, Ecliptaprostrata, Aster tataricus, Citrus reticulata peel, parched RhizomaAtractylodis, and Radix Glycyrrhizae as raw materials. The invention can effectively treat tuberculosis of intestine with notable curative effect and no adverse side effect. ${ }^{(49)}$

Cervical lymph node tuberculosis treatment traditional Chinese medicine CN 103845422 A - The invention belongs to a traditional Chinese medicine, specifically to a cervical lymph node tuberculosis treatment traditional Chinese medicine, which is characterized by comprising, by weight, 20-40 g of white paeony root, 10-20 g of bupleurumchinense, and 10-20 g of tuckahoe, wherein the selected white paeony root, the selected bupleurumchinense and the selected tuckahoe are washed, are subjected to air-drying, and are grinded into fine powder with a particle size of 100 mesh, and the one part of the obtained drug powder is directly and orally taken twice a day. According to the present invention, based on the Chinese medical science syndrome differentiation theory, characteristics of simple formula, easily available materials, low cost, high treatment effect, no toxic-side effect and effective cervical lymph node tuberculosis treatment are provided. ${ }^{(50)}$

Chinese Formulations - Compound preparations. It has been proved that Feitai Capsule, ShenlingBaizhu Powder, Compound Astragalus Capsule, anti-phthisis capsule and other Chinese patent poly herbal drugs used in conjunction with chemotherapeutic drugs can promote the sputum negative conversion rate, cavity closure rate, and lesion absorption rate; meanwhile, they can also alleviate the toxic effects of anti-TB drugs, rapidly improve TB symptoms, and thereby increase the efficacy. ${ }^{(51)}$

\section{Turkish herbal Formulation}

Ankaferd Blood Stopper ${ }^{\circledR}$ (ABS) - a Turkish formulation which is a mixture of plant extracts prepared from Alpiniaofficinarum, Glycyrrhizaglabra, Thymus vulgaris, Urticadioica and Vitisvinifera, has homeostatic and anti- 
bacterial effects. ABS MIC values for various sensitive and resistant strains ranged between between $<1.37-21.88 \mu \mathrm{g} /$ $\mathrm{ml}$. It was shown that 16 fold diluted concentration of the topically used ABS solution was found to be active against tuberculosis bacilli in vitro. Thus ABS might be used as a supportive agent together with anti-tuberculous drugs during debridement of multiple drug-resistant M.tuberculosis caused osteomyelitis and lymphadenitis lesions. ${ }^{(52)}$

\section{UkrineImmunomodulator - Immunoxel (Dzherelo ${ }^{\mathrm{TM}}$ )} is an oral, herbal immunomodulator formulation containing water-alcohol extract of 27 medicinal plants used in Ukraine for adjunct therapy for Tuberculosis showed that immunotherapeutic intervention increased bodyweight and decreased the incidence of new opportunistic infections and caused Enhancement of efficacy of tuberculosis drugs in HIV-infected patients with active pulmonary tuberculosis. ${ }^{(53)}$

A study on the sublingualImmunoxelpreparation.along with standard Anti tuebrculous therapy showed that $1 \%$ of TB patients became sputum-negative and the conversion rate was independent of whether the subject was having multidrug-resistant TB or TB with HIV coinfection. ${ }^{(54)}$

\section{Conclusion}

It can be seen from this compilation that there is a wealthof herbs which have potential role in tuberculosis. It may be a surprise that many commonly used household remedies like condiments, spices vegetables and fruits have scientifically documented anti tubercular property. These can be consumed freely with out much restriction as they are also nutritional supplements.

Usage of other herbs on routine basis has the following restrictions.

They can be used as adjunct/supportive therapy only to enhance the activity of routine anti tuberculous drugsespecially in multi drug resistant tuberculosis and to prevent the adverse effects of drugs like INH, Rifampicin etc. and not as a sole therapy for Tuberculosis.

More over many of the herbs enumerated here need further clinical validation for their safety and efficacy before their routine use in TB except the ones which have already are use in alternate systems of medicine such as Ayurveda, Siddha etc. in which case only under the supervision of experts in both allopathy and the respective alternate system of medicine. This is essential as there may be drug interaction between the herb and routine drugs and there may be also adverse effects per se for the herbs apart from documented adverse effects for the anti- tuberculous drugs. Judicious use of combination of herbal drugs with routine antitubercular drugs may be of importance in managing toxicity of drugs and multidrug resistant strains in future.

\section{REFERENCES}

1. Masson M, Molnár E, Donoghue HD, Besra GS, Minnikin DE, et al. Osteological and Biomolecular Evidence of a 7000-Year Old Case of Hypertrophic Pulmonary Osteopathy Secondary to Tuberculosis from Neolithic Hungary. PLOS ONE 8(10): e78252 (2013).

2. http://umm.edu/Health/Medical-Reference-Guide/Complementary-andAlternative-Medicine-Guide/Condition/Tuberculosis.

3. Guleria RS1, Jain A, Tiwari V, Misra MK.Protective effect of green tea extract against the erythrocytic oxidative stress injury during M.tuberculosis infection in mice. Mol Cell Biochem. 2002 Jul;236(1-2):173-81.

4. Rao RR, Rao SS, Natarajan S, Venkataraman PR. Inhibition of M.tuberculosis by garlic extract. Nature 1946;157.

5. Liu YL, Liu ZP. Observing the Effect of Altride Enteric-Coated Soft Capsules Combined With Anti-tuberculosis Medicine on Pulmonary Tuberculosis. Zhong Guo Yi Liao Qian Yan 2008;3:23-5.

6. Zutshi RK, Singh R, Zutshi U, Johri RK, Atal CK. Influence of piperine on rifampicin blood levels in patients of pulmonary tuberculosis. The Journal of the Association of Physicians of India 1985, 33(3):223-224.

7. Sivakumar A, Jayaraman G. Anti-tuberculosis activity of commonly used medicinal plants of south India. J Med Plants Res. 2011;5:6881-6884.

8. Tekwu EM, Askun T, Kuete V, Nkengfack AE, Nyasse B, Etoa FX, Beng VP. Antibacterial activity of selected cameroonian dietary spices ethno-medically used against strains of M.tuberculosis. J Ethnopharmacol.2012;142:374-382. doi: 10.1016/j.jep.2012.05.003.

9. Said Maham, FatemehFallah, Gita Eslami, Sepideh Shamsafar, Rahele Radmanesh , BitaPourkaveh. The antimycobacterium activity of menthapiperita and menthe spicataethanolic extract against mycobacterium Bovis in comparison with isoniazid. Iran J Clin Infect Dis 2011 Vol 6 No. 2.

10. Mohamed Saleem TS, Christina AJM , Chidambaranathan N , Ravi V, Gauthaman K. Hepatoprotective activity of Annonasquamosa Linn. on experimental animal model. International Journal of Applied Research in Natural Products Vol. 1(3), pp. 1-7, Sep/0ct 2008.

11. John Wilson Nkya, Paul Erasto, Musa Chacha. Antimycobacterial and cytotoxicity activities of Moringaoleifera Lam extracts. American Journal of Research Communication, 2014, 2(9): 108-120.

12. Miri $P, B a e J$ and Lee DS. Antibacterial activity of [10]-gingerol and [12]-gingerol isolated from ginger rhizome against periodontal bacteria. Phytotherapy Res. 2008; 22:1446-1449.

13. Renu Gupta, Bandana Thakur, Pushpendra Singh , H.B. Singh , V.D. Sharma, V.M. Katoch, \& S.V.S. Chauhan Anti-tuberculosis activity of selected medicinal plants against multidrug resistant M.tuberculosis isolates. Indian J Med Res. 2010;131:809-13.

14. Prabu A, Hassan S, Prabuseenivasan, Shainaba AS, Hanna LE2, Kumar V.Andrographolide: A potent antituberculosis compound that targets Aminoglycoside 2'-N-acetyltransferase in M.tuberculosis. J Mol Graph Model. 2015 Sep; 61:133-40.

15. Ntutela S1, Smith P, Matika L, Mukinda J, Arendse H, Allie N, Estes DM, Mabusela W, Folb P, Steyn L, Johnson Q, Folk WR, Syce J, Jacobs M. Efficacy of Artemisia afraphytotherapy in experimental tuberculosis. Tuberculosis (Edinb). 2009 Dec;89 Suppl 1:S33-40.

16. Jawed Iqbal, Ajay Kumar \& Najmul Islam. Azadirachtaindica induced suppression of M.tuberculosis secreted proteins in human monocyte

17. IJSRM June 2015 Vol.:1, Issue:2 Importance of Herbal Remedies in the Treatment of HIV \& TB Infection Priyanka M. Mandhare, Bhagwat H. Garje , Amitkumar A. Khade.

18. Kuang TJ, Dong M, Song $P$, et al. In vitro antibacterial effects of berberine on M.tuberculosis. ZhongGuoZhong Yao ZaZhi 2001;26:867-8,

19. BehanmRafiee; SepidehGhani ; DavoudSadeghi ; ShojaatDashti Pour ; Nader Mosavari The Antibacterial Effects of Plantago Minor, Calendula Officinalis and 
Eucalyptus Polycarpa Extracts AgaintsM.tuberculosisInvitro . http://eprints. arums.ac.ir/5177/1/Minor.pdf.

20. Naga Swathi SreeKavuri, SravaniYangalasetti, VenkataRaoVutla. Anti-tubercular Activity of Leaf and Seed Extract of Carica papaya. InRaventipid: PlantaActiva, 2016(1): 1-3, 2015.

21. Raja A AbdulKapur M Fijju M and Mohamed Salique S. In vitro studies on Efflux pump Inhibition of Catharanthusroseus and piperine against ofloxacin resistant M.tuberculosis. International Journal of Pharmaceutical Science Invention.

22. http://www.mmh-mms.com/downloads/mp07chenopodiumambrosioides.pdf

23. Adeniyi BA, Groves MJ, Gangadharam PR. In vitro anti-mycobacterial activities of three species of Cola plant extracts (Sterculiaceae). Phytother Res. 2004 May;18(5):414-8.

24. Lall N, Meyer JJ. In vitro inhibition of drug-resistant and drug-sensitive strains of M.tuberculosis by ethnobotanically selected South African plants. J Ethnopharmacol 66: 347-54 6 (1999).

25. J. Graham Gurusiddesh B Hiremath, Basappa B Kaliwal.Antitubercular activity of the rhizome of Curcuma pseudomontana. International Journal of Pharmaceuticals and Health care Research 12/2013; 01(04):178-183.

26. Lall N1, Meyer JJ Inhibition of drug-sensitive and drug-resistant strains of M.tuberculosis by diospyrin, isolated from Eucleanatalensis. J Ethnopharmacol. 2001 Dec;78(2-3):213-6.

27. Saludes JP1, Garson MJ, Franzblau SG, Aguinaldo AM Antitubercular constituents from the hexane fraction of Morindacitrifolia Linn.(Rubiaceae). Phytother Res. 2002 Nov;16(7):683-5.

28. A-D.Burkill, H.M. The useful plants of West Tropical Africa families. Royal Gardens kew. (1985) 320 pp.

29. Ulubelen A1, Evren N, Tuzlaci E, Johansson C. Diterpenoids from the roots of Salvia hypargeia. J Nat Prod. 1988 Nov-Dec; 51(6):1178-83.

30. Balachandran C1, Duraipandiyan V, Al-Dhabi NA, Balakrishna K, Kalia NP, Rajput VS, Khan IA, Ignacimuthu S. Antimicrobial and Antimycobacterial Activities of Methyl Caffeate Isolated from Solanumtorvum Swartz. Fruit. Indian J Microbiol. 2012 Dec; 52(4):676-81.

31. P. K. Debnath, JaydebChattopadhyay, AchintyaMitra, AnjanAdhikari, MirzaSamsurAlam, S. K. Bandopadhyay, JayramHazra. Adjunct therapy of Ayurvedic medicine with anti tubercular drugs on the therapeutic management of pulmonary tuberculosis. J Ayurveda Integr Med. 2012 Jul-Sep; 3(3): 141-149.

32. PanomwanPanseeta a, KanlayaLomchoey a, SamranPrabpaib, PalangponKongsaeree b, c, ApichartSuksamrarn d, SomsakRuchirawat e, SunitSuksamrarn. Antiplasmodial and antimycobacterialcyclopeptide alkaloids from the root of Ziziphusmauritiana. Phytochemistry, 72 (2011), 909-915.

33. Muthulingam, M. Antihepatotoxic Effects of Boerhaaviadiffusa L. on Antituberculosis Drug, Rifampicin Induced Liver Injury in Rats. Journal of Pharmacology and Toxicology, 3(2), 75-83. (2008).

34. Ravi, V., Patel, S. S., Verma, N. K., Datta, D., \&Saleem, T. M. Hepatoprotective activity of Bombaxceiba Linn against isoniazid and rifampicin-induced toxicity in experimental rats. International Journal of Applied Research in Natural Products, 3(3), 19-26 (2010).

35. Jehangir, A., Nagi, A. H., Shahzad, M., \& Azam, Z. Thehepato-protective effect of Cassia fistula (amaltas) leaves in isoniazid and rifampicin induced hepatotoxicity in rodents. Biomedica, 26(2), (2010).

36. Soni, R. K., Dixit, V., Irchhaiya, R., \&Alok, Spotential herbal hepatoprotective plants: an overviews. International Journal of Pharmaceutical Sciences and Research, 5(3), 774, (2014).

37. Meghna R Adhvaryu, Narsimha M Reddy, and Bhasker C Vakharia. Prevention of hepatotoxicity due to anti tuberculosis treatment: A novel integrative approach. World J Gastroenterol. 2008 Aug 14; 14(30): 4753-4762.
38. Balakrishnan, B. R., Sangameswaran, B., \&Bhaskar, V. H. Effect of methanol extract of Cuscutareflexa aerial parts on hepatotoxicity induced by antitubercular drugs in rats. International Journal of Applied Research in Natural Products, 3(1), 18-22. (2010).

39. Panda, V. S., Ashar, H. D., \&Sharan, A.Antioxidant and hepatoprotective effects of Garciniaindica fruit rind in antitubercular drug-induced liver injury in rats. Botanics: Targets \& Therapy, 3. (2013).

40. Karunamoorthi, K., Jegajeevanram, K., Vijayalakshmi, J., \& Mengistie, E. Traditional Medicinal Plants A Source of Phytotherapeutic Modality in ResourceConstrained Health Care Settings. Journal of Evidence-Based Complementary \& Alternative Medicine, 18(1), 67-74. (2013).

41. Dhamal, N., Patel, M., \&Pawar, S. Evaluation of Jasminumgrandiflorum for hepatoprotective activity in isoniazid induced liver damage. Internat J Pharm Sci Res, 3, 2568-2573. (2012).

42. Razvi Syed Ubaid, Kothekar Mudgal Anantrao, Jaju J. B. and Md. Mateenuddin. Effect of Ocimum sanctum (os) leaf extract on hepatotoxicity induced by antitubercular drugs in rats. Indian J PhysiolPharmacol 2003; 47(4) 465-470.

43. Jeyakumar, R., Rajesh, R., Meena, B., Rajaprabhu, D., Ganesan, B., Buddhan, S., \&Anandan, R . Antihepatotoxic effect of Picrorhizakurroa on mitochondrial defense system in antitubercular drugs (isoniazid and rifampicin)-induced hepatitis in rats. Journal of Medicinal Plants Research, 2(1), 17-19 (2008).

44. Y K Sharma, Harbans Singh and B L Mehra. Hepatoprotective effect of few Ayurvedic herbs in patients receiving antituberculus treatment. Indian Journal of Traditional Knowledge Vol. 3(4), October 2004, pp. 391-396.

45. Wang SY, Wang XL, Liu MM. Experimental study of effects of Chinese bulbul extracts againstingM.tuberculosis in vitro. Shi Zhen Guo Yi Guo Yao 2011;22:2965-6.

46. Geetha, K. M., Patil, V., \&Murugan, V. Hepatoprotective activity of aqueous alcoholic (70\%) extract of Rhodomyrtustomentosa (Aiton) Hassk against antitubercular drugs induced hepatic damage. International Journal of Green Pharmacy, 6(4), 295. (2012).

47. Chen CS, Liang Y.Analysis of the potency of matrine in the inhibition of mycobacteritum tuberculosis. Shou Du Yi Yao 2006;13:44.

48. Jatav, S. K., Kulshrestha, A., Zacharia, A., Singh, N., Tejovathi, G., Bisen, P. S., \& Prasad, G. B. K. S. Spirulina maxima protects liver from Isoniazid and Rifampicin drug toxicity. Journal of evidence-based complementary \& alternative medicine, 19(3),189-194.(2014).

50. http://www.google.com/patents/CN103845422A?cl=en.

51. Xia Zhang, Jing Guo. Advances in the treatment of pulmonary tuberculosis. J Thorac Dis 2012;4(6):617-623.

52. Deveci A1, Coban AY, TanrıverdiÇaycı Y, Acicbe 0, TaşdelenFışgın N, Akgüneş A, Ozatlı D, UzunM,Durupınar B. [In Vitro Effect of Ankaferd Blood Stopper ${ }^{\circledR}$, a Plant Extract Against Mycobacterium tuberculosis Isolates]. [Article in Turkish]. Mikrobiyol Bul. 2013 Jan;47(1):71-8.

53. Arjanova OV1, Prihoda ND, Yurchenko LV, Sokolenko NI, Vihrova LA, Pylypchuk VS, Frolov VM, Kutsyna GA. Enhancement of efficacy of tuberculosis drugs with Immunoxel (Dzherelo) in HIV-infected patients with active pulmonary tuberculosis. Immunotherapy. 2009 Jul;1(4):549-56. doi: 10.2217/imt. 09.25.

54. Efremenko YV1, Arjanova OV, Prihoda ND, Yurchenko LV, Sokolenko NI, Mospan IV, Pylypchuk VS, Rowe J,Jirathitikal V, Bourinbaiar AS, Kutsyna GA. Clinical validation of sublingual formulations of Immunoxel (Dzherelo) as an adjuvant immunotherapy in treatment of TB patients. Immunotherapy. 2012 Mar; 4(3):273-82. 